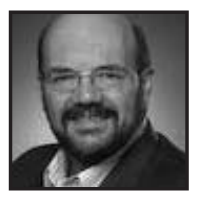

\title{
The Role of Education in Rural Communities
}

\author{
Tim Goddard, University of Prince Edward Island
}

\section{ABSTRACT}

Drawing upon a conversation held in rural Prince Edward Island, in this article I explore community questions regarding the role of education in Canada. I present five brief vignettes and then consider these through a lens that recognizes the criticality of community, context, and culture.

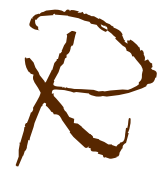

ecently I attended a meeting in a rural community on Prince Edward Island. The purpose of the meeting was to discuss the role of education, with a focus on how the education system could contribute to further economic and social development within both that specific community and also others in the local area. As I listened to the conversation, it struck me that the issues raised were not exclusive to that place and could, in fact, be considered as integral to the role of education in Canada. In this article I shall consider some of the challenges facing the education system in one part of Canada.

The discussions at the community I shall call Redsoil Creek covered the gamut of educational provision, for students of all ages. We considered both formal and informal education activities as well as delivery methods which ranged from the traditional to the esoteric. Other than me, none of the 15 participants had any professional connection to public education.

Redsoil Creek is a small collection of houses strung along a major highway. A rural road cuts across the highway at this point, and the community has grown up around that junction. It is a landscape of low rolling fields, mostly cleared, with some sections left as woodlots. There are numerous potato fields, a dairy farm with fields 
left to hay and silage, and a small general farm which operates a market garden. A small river (or large creek) winds its way along the valley parallel to the main road. In the community there is a gas station with a convenience store attached, an elementary school, two churches (one Roman Catholic, one Anglican), a high school serving villages up to an hour away by bus, a pottery where two CFAs (Come From Aways, or "Islanders By Choice" as some prefer) use a large garden shed to construct ceramics for the summer tourist trade, and two homes with hopeful tole-painted Bed and Breakfast signs swinging in the constant breeze. Most of the people who live in Redsoil Creek are seasonally employed, although a number of them drive down the road each morning in their commute to the nearest city. There is one small manufacturing plant a few kilometres away, with some skilled welders and machinists employed there, and the local farms employ general labourers to drive the cattle, drill the potato fields, and care for the fruit trees in the orchards. Generally, however, the farms are family concerns and do not provide many employment opportunities to the wider community.

\section{A Range of Issues}

The people at the meeting identified five areas of concern and it was apparent that the education system, broadly defined, was considered crucial to community health. The conversations covered the full human life span, ranging from kindergarten to senior's college.

\section{Kindergarten}

In Prince Edward Island the kindergarten system has, for the past ten years, been publicly funded but privately delivered. Children who are under five years of age attend an Early Childhood Centre and then, when they go to school, enter Grade One. Many of the early childhood educators are mothers who live within the community. They are required to have completed a two-year community college diploma. This system is now changing and kindergarten is being incorporated into the public school system.

The transition requires early childhood educators to complete a Bachelor of Education degree and a major question for the community is how they might do that while continuing to work in their classrooms. There is concern that people may have to leave their homes and families, and give up their work, in order to complete their degree. The University of Prince Edward Island, working closely with the Department of Education and Early Childhood Development and other stakeholders, has 
designed an innovative Bachelor of Education (Kindergarten) degree which builds on the experiential and educational experiences of the candidates and provides them with courses on a part-time basis. Classes are to be offered on a part-time basis during evenings, weekends and summer schools, allowing the degree to be completed over a six-year period. Further, the courses are to be offered in the east, west, and central parts of the Island, so that candidates do not all have to drive to Charlottetown. In this way, the University is trying to bring its educational programs to the people and hopes to minimize the stress faced by the working mothers who are being required to suddenly enter postsecondary education if they wish to keep their jobs.

\section{School graduates}

A second issue concerns the continuing exodus of young high school graduates, who leave the area almost as soon as they leave school. This rural depopulation not only strips the community of the next generation of entrepreneurs, managers and workers, but also reduces the number of young parents - and thus, children -in the region. Although Canada spends a high proportion of its gross domestic product on education (Brockington, 2009; UNICEF, 2008), the progress in high school graduation rates remains comparatively modest. The achievement of a high school graduation diploma is considered a crucial measure of success within the education system, and some $\$ 50$ billion is being spent annually on the $\mathrm{K}-12$ education system in Canada (Brockington, 2009). In Redsoil Creek, as in many other parts of the country, there are questions raised about the value of the education system and its appropriateness to local context.

Less than one third of high school graduates from Prince Edward Island directly enter a postsecondary institution for further education (Cobb, 2009). An argument made here is that when a school is driven by externally mandated curriculum and assessment protocols, and is not relevant to the local community, then the graduates who do not go away are not prepared for life in the community.

\section{Current workers}

A third question for the community relates to those workers who are employed and yet who both want and need continued skills upgrading. Such courses are only offered in the major centres of Charlottetown or Summerside, and to attend such programs means not only a major commute (in Island terms) but also time away from work. One local company has invested by providing courses to its own workers but such programs are, by definition, limited and limiting. A sheet metal worker may 
learn some new means of fabrication but this is unlikely to be a skill transferable to another workplace.

The lack of ongoing professional development opportunities means that both workers and industry become static. New methods of working pass by without anyone in Redsoil Creek becoming aware of their existence. New technologies accrue to competitors, whose products then become less expensive or more refined.

\section{Returning workers}

The collapse of industries based on natural resources, such as farming, forestry and the fishery, has thrown the lives of many people of working age in disarray. No longer able to pursue their trade, they do not have the skills needed to participate in the modern knowledge-based economy. The availability and delivery of retraining efforts is a fourth concern of many in the community.

This situation is exacerbated by the traditional transition from school to work which took place with earlier generations. Young men (and sometimes women) would leave school before completing their grade 12 diploma examinations and would move seamlessly into one of the resource industries. Jobs as loggers were plentiful, and those whose family owned fishing licences were able to enter the fishery. As a result they do not have the academic skills and formal qualifications required for work in the knowledge economy of the twenty-first century. The skills honed as first mate on a fishing boat do not easily match with those required for employment in a call centre.

\section{Retired workers}

The fifth question arises out of the experiences of the retirees, some of whom have spent their whole lives in the Redsoil Creek area but others who are either new or newly returned. Some have left other communities and have decided to retire on Prince Edward Island, others have returned after a working life spent in other parts of Canada or abroad. These older members of the community are seeking opportunities to enjoy their retirement and to continue to contribute to the social fabric of the region.

For many, the prospect of a quiet and bucolic retirement soon loses its charm. They are comfortable with an unpaid life but are looking for a filled-out life, one in which they continue to learn and to contribute. Programs such as Senior's 
College, where those with expertise in a field lead their peers in a voyage of discovery, require organization and facilitation skills which must be carefully administered if they are not to be confused with bossiness and superiority.

\section{Toward a New Paradigm}

These five communities of concern, extending from the early years to the senior years, were identified during a community discussion. It is important to consider ways by which these issues might be addressed.

It is clear that for the people of Redsoil Creek the formal education system has not worked. The kindergarten teachers are bound to the structural limitations of policy as they face the trauma of transition to a new system. Graduates of the high school have limited opportunities and are educated in a curriculum of little direct relevance. Those who have the skills to attend postsecondary education have to leave the community to do so-and rarely return. The workers who require skills upgrading are prevented by geography from accessing available programs. Those seeking a move from collapsing industries to the new economy are finding that they do not have the skills required. Those who have retired have few options for engagement. The dismembering of education into discrete sections has resulted in the differentiation of services and the separation of educational experiences by age, rather than by ability or interest.

However, if we were to view education through a lens which focused on the strengths, rather than the liabilities, of the community then perhaps a different picture would emerge. Theories of asset-based community development (e.g., Kretzmann \& McKnight, 1993; Mathie \& Cunningham, 2005), provide a lens which helps us view socioeconomic development in a way that recognizes the criticality of community, context, and culture.

The content of the curriculum needs to be contested. It has become the norm to have teachers saying that they do not have time to teach, they have to cover the curriculum. Similarly, the fetish of league tables and school rankings has resulted in a focus on the measuring and assessment of knowledge, rather than the construction of that knowledge. Programs such as guided apprenticeships and co-op placements need to be given school credit and equal status to pre-university academic courses. 
If we were to permit our schools to focus on the teaching of the skills and knowledge required to contribute to the continued growth and revitalization of community, then perhaps new graduates would be better prepared to function within their community. If we were to encourage the delivery of education programs at a variety of times, and using a variety of delivery media, perhaps the transitions between education and work would become less distinct and more open to all citizens.

The organization of education in Canada has evolved in a responsive rather than proactive manner. It has remained externally driven, with policymakers located in central urban conurbations making decisions affecting the operational aspects of schools across the jurisdiction. There is a need for Canadian education to return to a local locus of control, and to have decisions made at the point closest to where they are applied. Through the reallocation of resources from central to community control, the people of Redsoil Creek would be able to design and deliver an education system which contributed to economic and social development within the region.

\section{References}

Brockington, R. (2009). Summary public school indicators for the Provinces and Territories, 2000/2001 to 2006/2007. Retrieved March 14, 2010, from http://www.statcan.gc.ca /pub/81-595-m/81-595-m2009078eng.pdf

Cobb, G. (2009). Enhancing the human capital of the population. Presentation to the Senior Management Group, University of Prince Edward Island, April 27.

Kretzmann, J., \& McKnight, J. P. (1993). Building communities from the inside out: A path towards finding and mobilizing a community's assets. Evanston, IL: Northwest University, Centre for Urban Affairs and Policy Research.
Mathie, A., \& Cunningham, G. (2005). Who is driving development? Reflections on the transformative potential of asset-based community development. Canadian Journal of Development Studies, 26(1), 175-187.

UNICEF (2008). Education statistics, Canada. Retrieved December 18, 2009, from http://www.childinfo.org/files/IND_Canada. pdf 


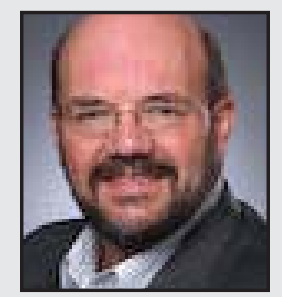

Tim Goddard is Dean of the Faculty of Education at the University of Prince Edward Island. He took up this role in July 2008.

Dr. Goddard has worked as a teacher, principal, superintendent of schools, university professor and education consultant. Internationally, he has extensive experience in England, Kosovo, Lebanon, Papua New Guinea, Slovenia and Sweden. Within the Canadian context he has lived and worked in Alberta, Saskatchewan, Nunavut, Nova Scotia and P.E.I.

Dr. Goddard's primary area of research and teaching is educational leadership and administration, broadly defined, with a focus on the role and impact of cultural and demographic change on structural systems within schools, particularly those serving minority and marginalized populations. 